\title{
"PRESENTE DE GREGO": UMA DINÂMICA PARA COMBATE DO AEDES AEGYPTI, O MOSQUITO DOS VÁRIOS VÍRUS
}

\section{“GREEK GIFT", A DYNAMIC TO COMBAT AEDES AEGYPTI, THE MOSQUITO OF MANY VIRUSES}

\author{
Sara Torres* \\ ORCID: https://orcid.org/0000-0002-9697-076X \\ Yury Lizeth Cardozo Prada** \\ ORCID: https://orcid.org/0000-0001-9059-9798 \\ Jean Avemir Rios*** \\ ORCID: https://orcid.org/0000-0003-4615-9685 \\ Elaine Della Giustina Soares**** \\ ORCID: https://orcid.org/0000-0003-1915-6585 \\ Cristian Antonio Rojas***** \\ ORCID: https://orcid.org/0000-0002-9085-6261 \\ Carmen Justina Gamarra****** \\ ORCID: https://orcid.org/0000-0003-4029-3859
}

\section{Resumo}

O projeto de extensão "Conhecendo o Aedes aegypti e Aedes albopictus, os mosquitos dos vários vírus", desenvolve uma série de atividades que, utilizadas em conjunto, visam mediar o aprendizado sobre os mosquitos e as doenças por eles causadas. Aliando a informação científica à ludicidade, busca-se facilitar o aprendizado por parte das crianças e oportunizar a mudança de atitudes, sendo a brincadeira o ponto de contato entre o aprendizado teórico e a vivência prática. Neste artigo, apresenta-se a atividade "Presente de Grego", uma garrafa de plástico enfeitada com tampa lacrada, contendo aparentemente apenas água. No entanto, no seu interior, de forma imperceptível, há ovos de Aedes aegypti que acabarão eclodindo. A dinâmica propicia uma situação controlada e segura, em que a criança tem contato com a descoberta pelo debate com os colegas sobre as transformações observadas, acompanhando o ciclo de vida do mosquito e verificando que em água parada, aparentemente inerte, rapidamente pode-se ter uma nova geração de mosquitos. Busca-se, com este projeto, trazer mudanças de atitudes que sejam permanentes e apresentar uma nova ferramenta lúdica que pode ser utilizada em diversos contextos pedagógicos.

Palavras-chave: Aedes; Jogos e brinquedos; Arboviroses; Crianças.

\begin{abstract}
The university extension project "Knowing Aedes aegypti and Aedes albopictus, the mosquitoes of many viruses" develops activities which aim to mediate learning about these mosquitoes and the diseases caused by them. Combining scientific information and playfulness, it seeks to facilitate children's learning providing them opportunities for changing attitudes through theoretical learning and practical experience. This article presents the activity "Greek gift", a decorated plastic bottle with a sealed lid, containing, apparently, just water. However, inside, imperceptibly, there are eggs of Aedes aegypti that will eventually hatch. It is a controlled and safe experience in which children discover, through observation and discussion with classmates, the transformations in the mosquito life cycle, realizing that still water can be the place where mosquitoes reproduce very fast. The project seeks to change permanently attitudes as well as to present, throughout this article, a new playful tool that can be used in different pedagogical contexts.
\end{abstract}

Keywords: Aedes; Games and toys; Arboviruses; Children.

Data recebimento: $29 / 09 / 2020$

Data de aceite: $08 / 04 / 2021$
* Aluna de Graduação da Universidade Federal da Integração Latino-Americana (UNILA), Foz do Iguaçu - PR, Brasil. E-mail: sara.torres2307@gmail.com

** Aluna de Mestrado da Universidade Estadual do Oeste do Paraná (UNIOESTE), Foz do Iguaçu - PR, Brasil. E-mail: jujulizeth@gmail.com *** Graduação. Faculdade União das Américas (UNIAMÉRICA), Foz do Iguaçu - PR, Brasil. E-mail: jeanavemir@hotmail.com **** Professora da Universidade Federal da Integração Latino-Americana (UNILA), Foz do Iguaçu - PR, Brasil. E-mail: elaine.soares@unila.edu.br ***** Professor da Universidade Federal da Integração Latino-Americana (UNILA), Foz do Iguaçu - PR, Brasil. E-mail: cristian.rojas@unila.edu.br ******* Professora da Universidade Federal da Integração Latino-Americana (UNILA), Foz do Iguaçu - PR, Brasil. E-mail:carmen.gamarra@unila.edu.br 


\section{Introdução}

No Brasil, assim como na maioria dos países da América Latina, as medidas de prevenção e controle das arboviroses focam principalmente no combate ao vetor (Brasil. Ministério da Saúde). O Plano Nacional de Controle da Dengue do Brasil prevê ações prioritárias como a promoção de campanhas informativas e mobilização das pessoas com o intuito de atribuir às famílias a responsabilidade da manutenção de seu ambiente livre de potenciais criadouros do vetor e estimular a atuação multissetorial, dentre outras (PESSOA et al, 2016).

Segundo as Diretrizes Nacionais para prevenção e controle de epidemias de dengue (BRASIL, 2009), iniciativas intersetoriais de combate ao mosquito vêm sendo desenvolvidas das mais diversas formas, com marcada participação do setor da educação, o qual tem sido foco de campanha de conscientização e de mobilização.

Uma das formas de trazer consciência e mudança de atitude pode resultar do aprendizado mediado pelo brincar. Por meio de jogos e outras atividades, é possível que as crianças vivenciem situações práticas, absorvam, reinterpretem a realidade e interajam para a solução de problemas (DALLABONA; MENDES, 2004). Autores como Piaget (2013), Roussou (2004), Vygotsky (1967) têm falado sobre a importância do jogo no processo de aprendizagem. Por intermédio do lúdico, a criança satisfaz, em grande parte, seus interesses, necessidades e desejos particulares, sendo um meio privilegiado de inserção na realidade, pois expressa a maneira como a criança reflete, ordena, desorganiza, desconstrói e reconstrói o mundo. Sendo assim, é uma das maneiras mais eficazes da criança trabalhar, refletir e descobrir o mundo que a cerca (ALMEIDA, 2009; NILES, 2015).

Partindo dessa premissa, para colaborar com as ações de mobilização e combate ao mosquito em Foz do Iguaçu, desde 2013, tem-se desenvolvido o projeto de extensão "Conhecendo o Aedes aegypti e Aedes albopictus, os mosquitos dos vários vírus", da Universidade Federal da Integração Latino-Americana (UNILA), em escolas municipais da cidade. $\mathrm{O}$ referido projeto visa à apresentação às crianças da rede pública de ensino de $\mathrm{Foz}$ do Iguaçu - PR educação sanitária e promoção da saúde e cidadania. A equipe extensionista adotou métodos lúdico-pedagógicos de ensino para, além de respeitar o ritmo de aprendizado de cada criança, instigá-las na busca por conhecimento a fim de tornarem-se multiplicadoras em sua comunidade.

Neste artigo, apresentam-se as caraterísticas gerais do projeto de extensão e uma das atividades lúdicas que fazem parte da ação extensionista denominada "Presente de Grego". Não se pretende avaliar a eficiência da atividade na aprendizagem das crianças ou na percepção do público envolvido no projeto, uma vez que essa avaliação é feita no âmbito geral do projeto e não em suas atividades específicas, pois todas as atividades propostas contribuem na construção do conhecimento do aluno. O objetivo pertinente é apresentar essa atividade para que outros educadores possam agregá-la em seus próprios programas pedagógicos. 


\section{Metodologia}

\section{Equipe de trabalho}

O projeto de extensão "Conhecendo o Aedes aegypti e Aedes albopictus, os mosquitos dos vários vírus" é executado por uma equipe multidisciplinar, que envolve discentes e docentes dos cursos de Biotecnologia, Ciências Biológicas e Saúde Coletiva da Universidade Federal da Integração Latino-Americana (UNILA), em parceria com o Centro de Controle em Zoonoses (CCZ) do município de Foz do Iguaçu, desde 2013.

\section{Detalhamento do público envolvido e caracterização do espaço:}

A cada ano, com vistas à execução das ações do projeto, uma escola municipal da cidade é selecionada de forma não aleatória, geralmente por demanda da coordenação da escola, onde toda a comunidade escolar é envolvida, conforme o público-alvo do projeto.

As ações extensionistas são desenvolvidas nas dependências da escola participante, sendo dez encontros semanais de, aproximadamente, uma hora cada. Dos primeiros nove encontros, participam somente os alunos da sala do $4^{\circ}$ ou do $5^{\circ}$ ano (em média 30 crianças de 9 a 12 anos de idade) e o docente das turmas. São trabalhados assuntos como ecologia do mosquito, transmissão do vírus, apresentação e identificação de focos de proliferação do inseto, ciclo de vida do Aedes aegypti. Comumente, aplica-se uma dinâmica lúdica criada ou adaptada pela equipe extensionista. No décimo e último encontro, é realizada uma apresentação ou socialização para toda a comunidade escolar, na qual as crianças são as protagonistas, tornando-se multiplicadoras dos temas desenvolvidos no projeto.

O "Presente de Grego" é uma dinâmica implantada no projeto de extensão para mostrar o risco que representa deixar água disponível para proliferação do mosquito. Essa atividade pretende aumentar o interesse das crianças participantes e a curiosidade das mesmas sobre o assunto, apresentando o ciclo de vida do mosquito de forma lúdica e deixando claro que sem água esse ciclo não se completa (NELSON et al, 1986). A representação do presente consiste numa garrafa PET enfeitada, dentro de uma caixa de papelão, contendo água (é o que as crianças veem de imediato), no entanto, na garrafa, com tampa lacrada, de forma imperceptível, há ovos de Aedes aegypti que acabarão eclodindo. A essa garrafa denominouse "presente de grego" pelo fato da espécie ser vetor de vários vírus e o fato da presença dessa ameaça biológica estar oculta.

\section{Coleta dos ovos do Aedes aegypti}

Os ovos são fornecidos pelo CCZ e ou coletados pela equipe do projeto de extensão. Para a coleta, procede-se da seguinte forma: cada extensionista é responsável por colocar e recolher uma armadilha de ovos em locais próximos ao seu domicílio. A armadilha ou ovitrampa 
(Figura 1) é um recipiente escuro e cilíndrico preenchido com água pura até a sua metade, baseado no modelo original do trabalho de Fay e Elliason e utilizado amplamente em trabalhos de captura de ovos (FAY; ELIASON, 1966; MARQUES et al., 1993; Brasil. Ministério da Saúde). Uma placa de material semelhante à madeira (Eucatex), de formato retangular (palheta), é colocada verticalmente e fixada no recipiente com o auxílio de um clipe, ficando parcialmente submersa na água. Assim, a superfície da palheta que estiver no limite do contato com a água servirá como local de oviposição do mosquito fêmea. Após três dias dessa exposição, as palhetas são recolhidas, os ovos são removidos delicadamente com auxílio de um alfinete, a água é descartada e o recipiente recolhido do ambiente. Deve-se evitar manter a armadilha exposta por mais tempo sob risco de eclosão dos ovos, com isso a armadilha poderá se configurar como criadouro potencial.

Figura 1 - Armadilha montada

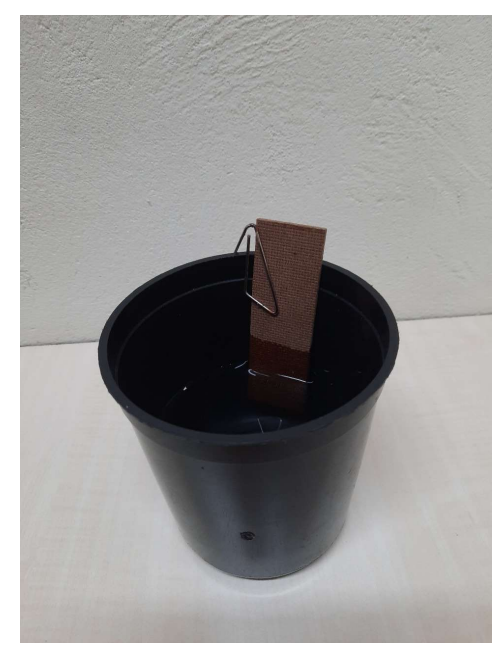

Fonte: Autores, 2020

\section{Construção do "presente de grego"}

Numa garrafa PET transparente com capacidade de 2 litros, coloca-se $700 \mathrm{ml}$ de água filtrada (para retirar resíduo de cloro) e 1 gr de ração para gato (matéria orgânica) triturada o suficiente para que não fique à mostra e possa manter o líquido transparente. Na sequência, são introduzidos de 7 a 10 ovos de Aedes aegypti, procedendo-se o lacre da garrafa, colocando cola quente na tampa para garantir a segurança de todos os envolvidos. 
Figura 2 - Garrafa com água, ração para gato e recipiente com ovos de Aedes



Fonte: Autores, 2020

\section{Decoração e enfeite do presente}

Para estimular a atenção das crianças é fundamental decorar e colorir a garrafa e a caixa do presente. A palavra AEDES escreve-se com letras gregas $(\alpha \varepsilon \delta \varepsilon \sigma)$ para instigar as crianças, tanto sobre o significado da palavra quanto para o conteúdo daquela "água misteriosa".

Figura 3 - Ovitrampa (à esquerda) "Presente de Grego" (concluído) para ser entregue às crianças

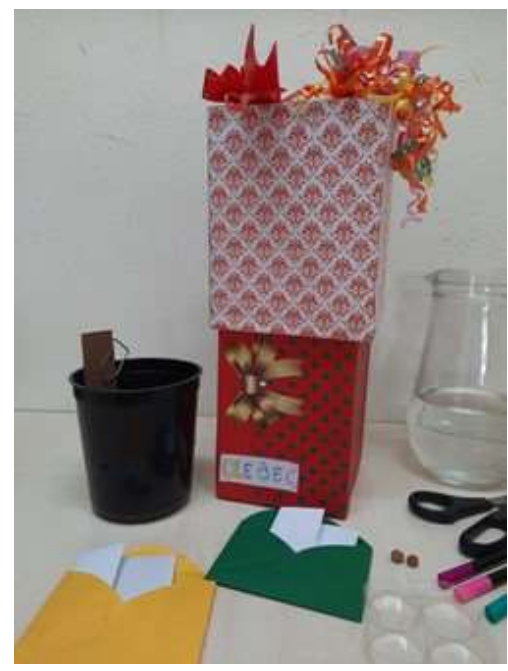

Fonte: Autores, 2020 


\section{As cartas}

Junto ao "presente de grego" são anexadas duas cartas bem objetivas escritas pelos extensionistas, pois é importante que o texto seja breve e não deixe pistas. Na sequência, são apresentadas essas cartas.

Conteúdo da primeira carta:

"Foz do Iguaçu, 16 de setembro de 2019.

Olá, amiguinhos!

A nossa equipe gosta muito de vocês e por esse motivo estamos presenteando com esta garrafa que preparamos com muito carinho para vocês. É uma espécie de presente surpresa e em alguns dias vocês saberão do que se trata. Junto a ela vai uma segunda carta que a professora vai ler para vocês daqui a uma semana. Fiquem atentos e cuidem da garrafa. Até mais.

Abraços,

Equipe do projeto Aedes"

Conteúdo da segunda carta:

"Foz do Iguaçu, 23 de setembro de 2019.

Olá, amiguinhos!

Já devem ter percebido que o nosso presente poderia ser considerado como um "presente de grego" porque na verdade a garrafa tinha mosquitos "escondidos". Esses mosquitos podem transmitir muitas doenças graves. Na verdade, a gente só colocou ovos de mosquito em um pouco de água e isso já foi suficiente para nascerem mosquitos. Olha que perigo! Se você deixar só um pouquinho de água no quintal ou na rua, os mosquitos vão colocar ovos e assim vai ter ainda mais mosquitos que podem transmitir Dengue, Zika, Chikungunya e outras doenças. Então queremos pedir que você não vá pelo mundo deixando "presentes de grego" para as outras pessoas.

A gente fez uma brincadeira com vocês. Os mosquitos do nosso presente estão "presos" e não podem escapar, então não há perigo, mas a água parada das garrafas, copinhos e até tampinhas de garrafa podem servir de criadouros de mosquitos, então fiquem de olho nas suas casas e nos seus bairros e avisem aos adultos se vocês encontrarem algum.

Abraços,

Equipe do projeto Aedes" 


\section{Entrega do "presente de grego"}

A concessão do presente ocorre no primeiro encontro com as crianças, após a apresentação de cada integrante do grupo extensionista. Inicialmente, entrega-se o presente a apenas uma turma do $4^{\circ}$ ou $5^{\circ}$ ano da escola, com crianças entre 9 e 12 anos de idade. Junto à garrafa, apresentam-se também as duas cartas, a primeira delas é lida imediatamente, enquanto a segunda só será aberta após uma semana, ficando sob a responsabilidade dos professores da sala.

Na próxima visita, antes da leitura da segunda carta, é explicado para as crianças o contexto e o significado de um "presente de grego". Até essa data, os ovos do mosquito Aedes aegypti já eclodiram, liberando as larvas, ou seja, a evolução do ciclo de vida do inseto seria agora capaz de ser vista através da garrafa, sendo que num primeiro momento encontrava-se transparente, contendo apenas "água”, aos olhos das crianças.

\section{Replicação do "presente de grego"}

Todo o processo de construção do "presente de grego" é replicado pela primeira turma, orientados pelos extensionistas e com a colaboração da professora da turma. Na sequência, as crianças procedem a entrega de um "presente de grego" a uma ou várias outras turmas, multiplicando assim a experiência com todas as crianças daquela escola.

\section{Critérios éticos}

As atividades foram desenvolvidas com a autorização e apoio da direção da escola, sendo inseridas na rotina das atividades das crianças. Os pais ou responsáveis foram informados, por meio de uma carta-termo, a respeito das atividades e solicitação de autorização para uso de imagem e voz. Para a repetição desta prática pelo leitor, o mesmo procedimento deve ser adotado.

\section{Resultados}

A aplicação da dinâmica do "presente de grego" foi introduzida no projeto de extensão "Conhecendo o Aedes aegypti e Aedes albopictus, os mosquitos dos vários vírus" com a finalidade de atrair a atenção das crianças, instigando-lhes a curiosidade e assim criando expectativas. Os resultados observados ao longo da aplicação da dinâmica são descritos a seguir:

- Reação de curiosidade, fascínio e satisfação das crianças. A curiosidade foi a primeira reação demonstrada pelas crianças, sendo fruto de um especial cuidado em preparar uma atmosfera de mistério em torno da apresentação da dinâmica, já que a ferramenta utilizada é a própria garrafa enfeitada (o presente), assim como a carta inicial. $\mathrm{O}$ fascínio é atingido com o surgimento inesperado das larvas e o subsequente desenvolvimento, acompanhado em tempo real pelas crianças, e a satisfação é o resultado da revelação do mistério e da obtenção de um 
conhecimento, que pode ser utilizado para realizar a brincadeira com outras turmas da escola. Dessa maneira, o "presente de grego" propiciou que as crianças fossem "capturadas", criando um vínculo com a equipe e engajamento com as atividades. Esse gancho inicial foi fundamental para que as demais atividades fossem produtivas.

- A atitude das crianças na socialização, no evento que fecha o projeto em cada escola, demonstra o conhecimento adquirido a toda a comunidade escolar (outras crianças, pais e professores). Essa atuação nesses eventos tem sido marcada pelo protagonismo, o entusiasmo e o domínio do conhecimento. A figura 4 apresenta fotos da socialização, onde pode-se observar o engajamento das crianças, seu protagonismo perante a comunidade escolar e a participação dos extensionistas limitando-se ao acompanhamento do evento.

Figura 4 - Fotos do projeto "Conhecendo o Aedes aegypti e Aedes albopictus, os mosquitos dos vários vírus", no evento de socialização, na Escola municipal Candido Portinari

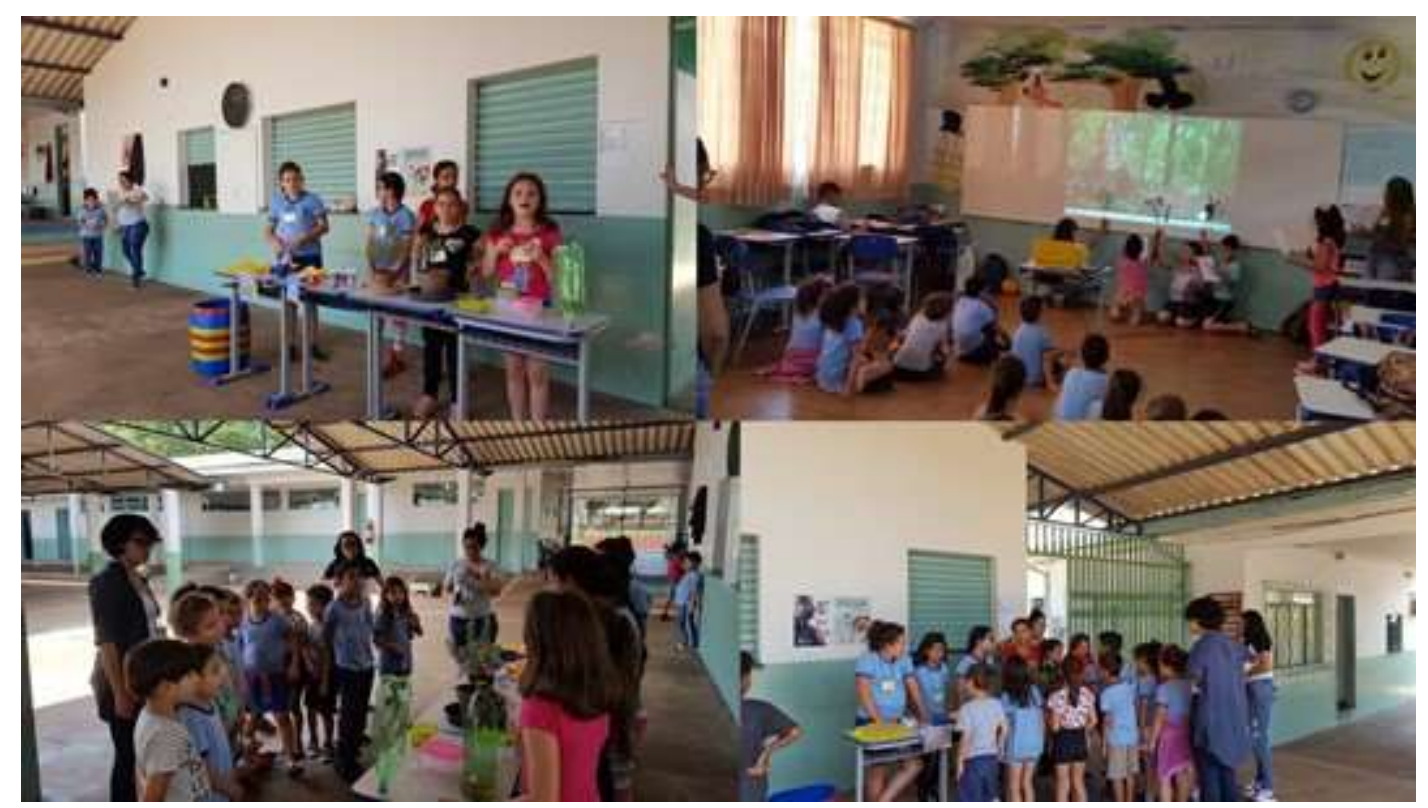

Fonte: Autores, 2020. Fotos realizadas com consentimento da escola e com autorização assinada pelo responsável de cada aluno

\section{Discussão}

Segundo uma antiga história grega, durante a guerra de Tróia, um cavalo de madeira foi deixado pelos gregos junto aos muros da cidade. Os troianos aceitaram o objeto como um presente e suposta rendição dos gregos à guerra, assim o levaram para dentro de seus muros (HOMERO, 2019). Contudo, ao anoitecer, quando os soldados troianos adormeceram, pois 
já estavam muito embriagados, saíram de dentro do cavalo soldados gregos que abriram os portões da cidade para que todo o exército entrasse e destruísse Tróia.

Logo, da expressão "presente de grego" tem-se algo que parece bom, mas que se revela como um grande pesadelo. É assim também com a garrafa, no início parece bastante insignificante ser presenteado com uma garrafa PET, contendo água, mas dentro dela há ovos de um inseto perigoso, os quais acabarão eclodindo (NATAL, 2002). Isso mostra para as crianças que o mosquito precisa apenas de um pouco de água para poder proliferar e um pouco de matéria orgânica, mas esse detalhe pode ser omitido para simplificação do conceito. E isso pode acontecer de forma muito silenciosa, passando despercebido para a maioria das pessoas que olha um recipiente abandonado na rua ou no seu próprio quintal.

Neste projeto, as crianças passam por três grandes emoções, avançando à medida em que são apresentadas explicações sobre o "presente de grego". São elas, curiosidade, fascinação e satisfação.

O primeiro sentimento experimentado pelas crianças é o de curiosidade e em alguns há uma certa indignação, uma vez que, além da entrega da garrafa e de uma carta não muito esclarecedora, elas não recebem mais informações a respeito da dinâmica, até um próximo encontro. Afinal, por que uma garrafa contendo água seria um presente? Pluck e Johnson (2011, p. 24) indicam que a falta de informações é importante para instigar a curiosidade e a tentativa de resolver essa falta é significativo para melhorar a aprendizagem. Os autores afirmam que "a curiosidade é um tipo de motivação intrínseca que tem grande potencial para melhorar a aprendizagem do aluno e pode ser utilizado na sala de aula, aplicável a quase qualquer disciplina acadêmica".

Depois da curiosidade inicial, os sentimentos manifestados pelas crianças são o fascínio e o encantamento. Manter as crianças engajadas e motivadas na escola é um desafio, mesmo para os professores mais experientes (KNÜPPE, 2006). Embora seja difícil, existem práticas que geralmente incentivam os alunos a se envolverem mais. Segundo Railsback (2002), "essas práticas incluem afastar-se do aprendizado mecânico e memorização para fornecer um trabalho mais desafiador e complexo, tendo um foco interdisciplinar e encorajando o aprendizado cooperativo". Nesse caso relatado, as crianças foram induzidas a observarem a garrafa diariamente, tentando descobrir o motivo dela ser um presente. Antes do próximo encontro com os extensionistas, sete dias entre a entrega do presente e a próxima visita, os ovos do Aedes já eclodiram, surgindo as larvas e, eventualmente, as pupas. Naquele momento, não se tratava somente de uma garrafa contendo água, havia "vida" nela e isso, aos olhos das crianças, tornou-se fascinante. Assim sendo, em visita à escola, posterior ao surgimento de larvas e pupas, ouviu-se relatos desse fascínio, tanto por parte da comunidade escolar quanto da equipe pedagógica, zeladoras, cozinheiras e professoras das classes vizinhas.

Dessa forma, o ciclo de emoções instigado neste experimento encerra-se com a satisfação de possuir um conhecimento novo, a resposta largamente desejada a uma pergunta. Essa emoção é sentida quando é feita a leitura da segunda carta para as crianças a respeito do 
material contido na garrafa, o porquê de tratarmos como um presente e o motivo de ser nomeado "presente de grego".

Em um extenso trabalho sobre o processo de aprendizado relacionado ao uso de videogames, o linguista James Paul Gee (2005) se pergunta qual é o profundo prazer que os humanos obtêm dos videogames? Ele chega à conclusão de que os bons videogames são tecnologias profundas que possibilitam a aprendizagem como uma forma de satisfação profunda e que os mesmos têm muito a dizer sobre como a aprendizagem poderia ser no futuro, quando as velhas práticas da escola tradicional fossem abandonadas (GEE, 2005).

Neste projeto, assim como em um jogo, no final também se obtém a satisfação e isso comtribui positivamente para o processo de aprendizagem vivenciado durante a execução do projeto.

A adoção de didáticas lúdicas para aplicação da metodologia do "presente de grego" é crucial para obtenção de um resultado positivo. Se os extensionistas não aplicassem uma metodologia lúdica ou não utilizassem recursos psicopedagógicos na execução dessa ação, não seria obtido o efeito esperado, o de concluir o ciclo de emoções infantis, explicado neste trabalho.

Cada detalhe conta. A primeira carta é um fator importante dentro do contexto de emoções das crianças, justamente porque ela aumenta a curiosidade e atenção dos menores para o que se tem ali ou porque uma garrafa com água seria tão importante. A ausência de pistas no bilhete favorece o raciocínio e somadas à escrita grega, estimulam a curiosidade, contemplada dia após dia, à medida que observam as mudanças surgidas na garrafa, segundo orientações fornecidas pela docente da turma.

A apresentação da história e do contexto de um presente de grego, seguida da leitura da segunda carta, permitem às crianças ter a ideia de que o presente dado era na verdade algo ruim. As crianças entendem o "presente de grego" e o quão perigoso pode ser deixar água disponível para proliferação do mosquito. Nesse momento, pode-se explicar às crianças que todos nós podemos, muitas vezes sem perceber, deixar "presentes de grego" para as pessoas que nem mesmo conhecemos, ou seja, todas as vezes que deixamos na rua uma garrafa, um saco de batatas fritas e outros sítios potenciais de oviposição.

A replicação de cada etapa e a entrega do "presente de grego" para cada uma das turmas de alunos da escola oferecem, principalmente ao primeiro grupo de crianças, uma oportunidade única. Eles se preparam, mostram concentração e entusiasmo, sendo que a partir de um dado momento eles mesmos serão os educadores e protagonistas dos processos de ensino e aprendizagem e do combate ao mosquito.

A didática do "presente de grego" tem se apresentado como uma metodologia que faz bom uso do ciclo de emoções infantis a fim de chegar à conscientização. O entendimento do contexto histórico do "presente de grego", juntamente com uma linguagem clara, explicativa e exemplificativa da segunda carta, além de ampliar o conhecimento cultural dessas crianças, promovem a conscientização a respeito das necessidades do Aedes e do quão fácil é para ele supri-las. Por esse motivo, considera-se que a dinâmica é passível de ser aproveitada em diferentes contextos. Por exemplo, um professor pode oferecer o presente aos seus alunos, junto 
com as duas cartas e, no fina, propor a eles ofereçam o presente para outra turma da escola. Da mesma forma, o "presente" pode ser utilizado em outros contextos pedagógicos, como em grupos de escoteiros, clubes de leitura, grupos religiosos, colônias de férias, entre outros.

\section{Conclusão}

Este trabalho destaca a importância das metodologias lúdicas de ensino na construção do aprendizado infantil. A expectativa é que as três emoções que as crianças foram motivadas a sentir com esta brincadeira: curiosidade, fascinação e satisfação, promovam conscientização, ligando a disponibilidade de água com a consequente possibilidade de proliferação do Aedes. A dinâmica do "presente de grego" é uma ferramenta de grande relevância para a abordagem dos assuntos referentes ao mosquito Aedes aegypti e as doenças que ele transmite, além de educação ambiental, educação sanitária e saúde pública.

Considera-se que esta metodologia pode ser aplicada em todas as escolas do Brasil e em outros países do continente, sendo que o combate ao mosquito é uma grande prioridade. A aplicação dos conhecimentos obtidos mediante a utilização do "presente de grego" incentiva e motiva as crianças a tornarem-se cidadãos conscientes da necessidade de zelar pela saúde individual, familiar e coletiva, sobretudo com o cuidado com o ambiente onde residem.

\section{Referências bibliográficas}

ALMEIDA, Anne. Ludicidade como instrumento pedagógico. Cooperativa do Fitness, Belo Horizonte, jan. 2009. Seção Publicação de Trabalhos. Disponível em: http: www.cdof.com.br/recrea22.htm. Acesso em set. 2020.

AMÂNCIO, Z. A. L. S., SANTOS, S. M., OLIVEIRA, E. S. F., CARVALHO, R. G., COELHO G. E. Estratégias de controle do Aedes aegypti: uma revisão. Epidemiol. Serv. Saúde, Brasília, v. 25, n. 2, p. 391-404. 2016.

Brasil. Ministério da Saúde (MS). Combate ao Aedes aegypti: prevenção e controle da Dengue, Chikungunya e Zika. Disponível em: https://www.saude.gov.br/saude-de-a-

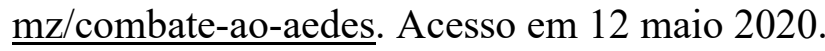

Brasil. Ministério da Saúde (MS). Secretaria de Vigilância em Saúde. Departamento de Vigilância Epidemiológica. Diretrizes nacionais para prevenção e controle de epidemias de dengue. MS, 2009. 160 p. - (Série A. Normas e Manuais Técnicos). ISBN 978-85-334-1602-4.

DALLABONA, S.R; MENDES, S.M.S. O lúdico na educação infantil: jogar, brincar, uma forma de educar. Revista de Divulgação Técnico-Científica do ICPG, 2004;1:107-12. 
FAY, R. W., ELIASON, D. A. A preferredoviposition site as a surveillancemethod for Aedes aegypti. Mosq news, v. 26, n. 4, p. 531-5, 1966.

GEE, J. P. Pleasure, learning, video games, and life: The projective stance. E-learning and Digital Media. 2005.

HOMERO. La Odisea. Amazon Digital Services LLC - KDP Print US. Disponível em: https://books.google.com.br/books?id=mRanyAEACAAJ. Acesso em 11 set. 2020.

KNÜPPE, L. Motivação e desmotivação: desafio para as professoras do ensino fundamental. Educar, Curitiba, v.27, p. 277-290, jan/jun .2006.

MARQUES, C. C. de A., MARQUES G.R. de A. M., BRITO, M. de, NETO, L. G. S. ISHIBASHI, V. de C., \& Gomes, F. de A. Estudo comparativo de eficácia de larvitrampas e ovitrampas para vigilância de vetores de dengue e febre amarela. Revista de Saúde Pública, 27, 237-241. 1993.

NATAL, D. Bioecologia do Aedes aegypti. Biológico, 64 (2), 205-207. 2002.

NELSON M. J. Aedes aegypti: Biology and Ecology. Washington DC: Pan American Health Organization, 1-59. 1986.

NILES, R. P., \&Socha, K. A importância das atividades lúdicas na Educação infantil. Ágora: Revista de divulgação científica, 19(1), 80-94. 2005.

https://doi.org/10.24302/agora.v19il.350. Acesso em 11 de Setembro de 2020.

PESSOA, João Paulo de Morais et al. Controle da dengue: os consensos produzidos por agentes de combate às endemias e agentes comunitários de saúde sobre as ações integradas. Ciência \& Saúde Coletiva [online]. 2016, v.21, n.8 [Acesso em: 11 set. 2020], pp. 23292338. Disponível em: $<$ https://doi.org/10.1590/1413-81232015218.05462016.

PIAGET, J. Play, dreams and imitation in childhood. v. 25. Routledge. 2013.

PLUCK, G., \& JOHNSON, H.L. Stimulating curiosity to enhance learning. GESJ:

Education Sciences and Psychology, v.2, 24-31. 2011.

RAILSBACK, J. Project-Based Instruction: Creating Excitement for Learning. By Request Series. 2002.

ROUSSOU, M. Learning by doing and learning through play: an exploration of interactivity in virtual environments for children. Computers in Entertainment (CIE), 2(1), 10. 2004.

VYGOTSKY, L. S. Play and its role in the mental development of the child. SovietPsychology, 5(3), 6-18. 1967. 